\title{
EDITORIAL
}

\section{Transmisión perinatal del virus de la inmunodeficiencia humana}

\author{
Jorge Enrique Martínez M., M.D.*
}

La transmisión perinatal constituye el mecanismo más efectivo para adquirir el virus productor de la Inmunodeficiencia Humana, después de la frecuencia dada por las transfusiones sanguíneas. A nivel mundial, se informa una prevalencia que va del 10 al $20 \%$ de infección perinatal y en cuanto a la posibilidad de adquirir el virus de la Inmunodeficiencia por vía placentaria, es un 30\% luego de la exposición al virus. En Colombia, a junio de 1991, sólo se habían reportado 20 casos de transmisión perinatal (1), con 9 decesos, mientras que en Estados Unidos, uno de los países más afectados, de los 19.652 casos en estadío 5 ó 6 reportados a los CDC hasta junio de 1991 (2), había 1.346 niños menores de 13 años afectados por el HIV, de los cuales el 78\% habían adquirido la enfermedad a través de las madres.

En los casos perinatales, la edad media del diagnóstico fue anterior a los dos años de edad, con igual distribución por sexos. Las madres de estos niños presentaban las siguientes características: el $54 \%$ eran usuarias de drogas intravenosas y el $26 \%$ eran compañeras de hombres infectados, de los cuales el 74\% eran drogadictos. Los diagnósticos más frecuentes fueron:

Nneumonía por Pneumocystes carinii $41 \%$

Neumonitis Linfoide Intersticial $38 \%$

Infecciones bacterianas recurrentes $27 \%$

El número de casos adquiridos en la vida perinatal van en aumento cada año. Se considera que en EE. UU. el número de niños infectados, nacidos de madres con HIV es del 30 al 50\%, como lo reporta el Estudio Colaborativo de Transmisión Perinatal de la Ciudad de New York (3), en donde la mitad de los niños infectados nacidos de madres seropositivas tuvieron resultados positivos mediante la prueba de amplificación genética o reacción en cadena de la polimerasa en el período neonatal; mientras tanto en Europa (European Colaborative Study (4), datos parciales en 1988) sobre 100 niños nacidos de madres con infección por HIV y seguidos durante 12 meses, se han reportado tasas de infección de aproximadamente el $24 \%$ y en Nairobi, Kenya, la tasa es del $45 \%$.

El diagnóstico de la infección por HIV en niños mediante la búsqueda de anticuerpos es difícil, principalmente debido a que la pérdida de los anticuerpos adquiridos de la madre pasivamente a través de la placenta, no ocurre antes de los 15 meses y porque además se han reportado casos de seroconversión en niños infectados con HIV. Por esto se ha insistido en la utilidad de la prueba de amplificación genética o reacción en cadena de la polimerasa para el diagnóstico temprano en estos casos (5-6).

La transmisión perinatal probablemente ocurra in útero o intrapartum, por exposición a la sangre materna o a fluidos contaminados; el HIV ha sido aislado de sangre del cordón y de tejidos fetales por Jovaisas en fetos de 20 semanas y Nzilambi en el Africa, lo cual apunta más hacia la primera opción. Esto sugiere que el riesgo de infección para el feto aumenta cuando la madre tiene evidencia clínica de la infección o cuando aparece una severa inmunodepresión en los momentos cercanos al parto.

También se ha reportado la adquisición de la infección a través de la lactancia materna en mujeres que han sido infectadas en el período del post-parto. Parece que el embarazo no altera la historia natural de la enfermedad en la madre.

Enfebrero de 1991 LANCET publicó el European Collaborative Study, realizado en 10 Clínicas europeas y terminado en junio de 1990, que comprendió un universo de 600 niños nacidos de madres infectadas por HIV (1-7). Se estudió la historia natural y el riesgo de transmisión mediante un seguimiento de 18 meses.

Al cierre de la investigación se había diagnosticado la infección por HIV a 64 niños y 18 de ellos ya presentaban la sintomatología de los estadios Vó VI de la enfermedado SIDA. Por esta época 9 habían fallecido en el estadio VI de la enfermedad, uno de ellos por el llamado Complejo Relacionado con el SIDA (AIDS Related Complex). Basados en la persistencia de anticuerpos que presentaron 27 infantes a lo largo del estudio, se les incluyó en el grupo anterior.

Del universo observado hubo 353 niños en quienes los anticuerpos adquiridos pasivamente de la madre desaparecieron y presumiblemente no estaban infectados.

En control posterior, por cultivo, se le aisló el virus a 10 de ellos con lo cual el grupo de seronegativos se redujo a 343, que fueron evaluados hasta los tres años de edad, encontrando que ninguno de ellos desarrolló SIDA, Inmunodeficiencia persistente $o$ volvió a presentar anticuerpos o antigenemia.

* Escuela de Medicina Juan N. Corpas. Profamilia, Bogotá. 
Las características clínicas iniciales de los niños infectados por el virus de la Inmunodeficiencia Humana Adquirida fueron linfadenopatía persistente y hepato-esplenomegalia en un $30 \%$ o bien la presencia de candidiasis oral seguida rápidamente de la instauración del cuadro de la Inmunodeficiencia.

El 83\% de los infectados mostró características clínicas y de laboratorio de afección por HIV a los 6 meses de edad. A los 12 meses el 29\% ya se encontraba en el Estadio Vó VI o SIDA y un 17\% de ellos había fallecido por afecciones relacionadas con el SIDA. La tasa de transmisión vertical fue del $12.9 \%$ y el virus se aisló repetidamente en el $2.5 \%$ de los niños que habían perdido los anticuerpos maternos y tenían un cuadro clínico e inmunológico normal; el rápido establecimiento de la enfermedad en cerca del 80 a $90 \%$ de los niños apunta mayormente hacia una transmisión in uterus que hacia la transmisión durante el parto.

Dos de los niños tuvieron sífilis congénita y otros síntomas menores de infección congénita por Citomegalo-virus.

Entre las madres, el 52\% eran usuarias de drogas psicotrópicas intravenosas, sólo el $2.8 \%$ tenía establecido el cuadro del SIDA en el momento del parto o dentro de los tres meses que le siguieron y el $2.2 \%$ tenía linfadenopatía generalizada como signo clínico.

Entre los hallazgos perinatales no hubo ningún signo que discriminara los niños infectados de los que no lo estaban, aunque hubo la tendencia en aquellos que había adquirido la infección a nacer más pronto, con peso más bajo y más pequeños, aunque estos datos no fueron estadísticamente significativos.

Entre los signos y síntomas asociados a la infección por HIV previos a la aparición del SIDA o estadíos terminales, hubo una alta incidencia de parotiditis y de candidiasis oral, ésta última por lo general se presentó dos meses antes de establecerse el cuadro, siendo altamente predictiva del inminente SIDA, ambas debidas a la anergia que presentan el sistema inmunológico. Esta situación ocurrió más veces en aquellos infantes infectados que entre los que no lo estaban. También estuvo fuertemente asociada la septicemia y la neumonía por bacterias gram-negativas con la infección por HIV. La encefalopatía y otros desórdenes neurológicos o falla en el desarrollo, no fueron comunes en el período pre-SIDA, aunque estuvieron asociados con infecciones. La linfadenopatía y la hepato-esplenomegalia fueron hallazgos comunes en los niños infectados.

Los indicadores de actividad inmunológica tales como el perfil de linfocitos $T$, la relación T4/T8 y las inmunoglobulinas A, G y M fueron claros parámetros que discriminaron entre los infantes no infectados de aquellos que presentaban el HIV.

Usualmente la hiperinmunoglobulinemia $G$, A y M fue la primera característica de la enfermedad en aparecer en un paciente, seguida de los signos y síntomas iniciales de la Inmunodeficiencia, la caída en la relación de T4/T8 y finalmente la instauración del SIDA, éstos se consideran hallazgos altamente específicos para el diagnóstico de la enfermedad en hijos de madres positivas, no siendo aplicables a la población en general, por su bajo valor predictivo.

Sobre la progresión de la enfermedad en los 64 niños seropositivos para los anti-cuerpos anti-HIV, el 60\% mostró alguna característica del SIDA a los 3 meses de edad, en el 30\% se instauró el cuadro en los primeros 6 meses, el 83\% a los 6 meses y un 90\% al año; de este grupo la mitad tenía baja en la relación T4/T8 y las 4/5 partes tenía hiperinmunoglobulinemia A, $G$ y M. Luego, la progresión hacia la fase final de la entidad fue lenta durante el seguimiento de dos años. Ninguno de los niños adquirió la enfermedad luego de los 20 meses de edad.

Además de esto, Joan Hittelman y col. (8) estudiaron 142 niños nacidos de madres infectadas por el HIV, encontrando que la mayoría de ellos presentaban alteraciones en la motilidad fina y gruesa, más notorios que en los pertenecientes al grupo control. Al cabo de 24 meses de la investigación, nueve de 18 tenían inhabilidad motora y 6 presentaban un claro retardo mental.

\section{BIBLIOGRAFIA}

1. Ministerio de Salud Pública de Colombia, División de Epidemiología; casos de SIDA reportados en el país a 8 de junio de 1981.

2. Angell M. A Dual Approach to the AIDS Epidemic. The New England Journal of Medicine 1991; 324(21): 1498-1500.

3. Carpenter C. et al. Natural history of AIDS in women in Rhode Island. American Journal of Medicine; 86(6): 771-775.

4. Berkelman R. et al. Epidemiology of HIV infection and Acquired Immunodeficiency Syndrome. American Journal of Medicine 1989; 86(6): 761-770.

5. Keller G. et al. Detection of HIV 1 DNA by Polymerase Chain Reaction Amplification and Capture Hybridization in microtiter wells, Journal of Clinical Microbiology 1991; 29(3): 638-640.
6. Ou Chin et al. DNA amplification for direct detection of HIV-1 in DNA of peripheral blood mononuclear cells. Science, 1988; 239(4837): 295297.

7. Ades A., Hewell H., Peckman C., European Collaborative Study. Children born to women with HIV-1 infection. Natural history and risk of infection. Lancet. 1991; 337(8736): 253-260.

8. Hittelman J. Severe Motor Disability in Pediatric HIV, Clinical Congress News. VII International Conference on AIDS 1991; 1(6): 4. 